\title{
Deadlines and Comprehensive Regulations
}

\author{
By Jonathan Porat
}

There is a large push by the United States government to improve the effectiveness and responsiveness of the US regulatory regime. Established proposals aim to improve US regulatory policy by making it easier for the public to use judicial review as a tool to respond to overly burdensome regulations. Much of the debate over the effectiveness of these proposals focuses on more visible regulatory outcomes. Unfortunately, the effect of judicial review on regulatory development is often overlooked. If judicial review promotes less comprehensive regulatory analysis through the presence of inflexible judicial deadlines, then regulatory reform promoting judicial review ironically may not prevent negative regulatory outcomes. This paper empirically measures whether regulations with judicial deadlines are developed less comprehensively than regulations with laxer statutory deadlines. This paper will determine how the differences in the development of regulations with judicial deadlines should influence the way that the government analyzes proposals for regulatory reform.

\section{Introduction}

On January 24, 2012, a littleknown United States Environmental Protection Agency (EPA) program became one of the most popular pieces of public policy in the country. In his 2012 State of the Union Address, President Barack Obama highlighted the Spill Prevention, Control, and Countermeasure (SPCC) rule as an example of why the US is in need of regulatory reform. The SPCC was authorized by the Clean Water Act, which gave the President the authority to regulate bulk oil containers to prevent potential oil spills near shorelines. The SPCC was designed to mainly regulate the oil and gas industry, but dairy farmers also fell under the regulation because milk contains animal fats, which classifies it as oil under the rule (US EPA 2012).

In an initial analysis of the SPCC, to comply with the regulation, dairy farmers would have to institute emergency management plans and train first responders in the event that milk spilled out of bulk containers. Farmers would even potentially install dikes to prevent a leak from a large tank of milk, butter, or yogurt (US EPA 2012). According to the Wall Street Journal, the US government set up a \$3 million a year program to help dairy farmers comply with these regulations (WSJ 2011). In the State of the Union Address, President Obama noted that SPCC compliance costs amounted to around $\$ 10,000$ annually. Those statistics led President Obama to joke: "With a rule like [the SPCC], I guess it was worth crying over spilled milk" (Obama 2012).

While the idea of mobilizing first responders to mitigate threats associated with mishandled dairy products provides fodder for plenty of milk-related word play, rules like the SPCC underscore a potential deficiency of the US regulatory system. Regulations, especially on the federal level, are complex and farreaching in scope. The breadth of these 
regulations means that seemingly minor aspects can have meaningful social outcomes. If the analyses behind regulations are not comprehensive enough, then rules might have negative outcomes that the government never intended.

An optimal regulation would be strong enough to respond to policy problems while not being overly burdensome to the public. Trying to understand how to prevent burdensome regulation while encouraging the government to act speedily and effectively is at the heart of President Obama's increased attention towards regulatory reform. The US government is searching to find a way to take meaningful regulatory action, while ensuring that it has fully anticipated all of the relevant costs and benefits of a regulation to prevent unintended negative outcomes (Obama 2011a, 2011b, 2012; Sunstein 2011). In an attempt to limit the negative outcomes of regulation, the US House of Representatives passed the Regulatory Accountability Act (RAA) in December 2011. The RAA makes it easier for the public to use litigation as a response to harmful regulation. The RAA specifically changes the criteria used to evaluate lawsuits from the public against regulatory agencies (House 2011). Based on court orders in response to public lawsuits, a court could decide to make issued regulations weaker or stricter and force agencies to regulate where there is currently inaction. The court would usually set and enforce judicial deadlines: deadlines that agencies must comply with in response to a court order. The judiciary's ability to effectively enforce court orders differentiates these deadlines because they are particularly inflexible (Gattuso 2011).

The RAA's ability to promote judicial review of regulations has elicited mixed reactions. The US Chamber of Commerce, a large lobbying organization representing many businesses and trade organizations, has come out in favor of this aspect of the RAA. It is arguing that by encouraging judicial review of regulations, the public can use litigation as a check against burden- some regulatory action (Chamber 2011a). The White House has come out against the RAA. In a statement of administration policy, the President declared that he would veto the RAA if it passed through the Senate (OMB 2011). The administration argued that the RAA would significantly hamper the ability of government agencies to meet program goals by adding exorbitant levels of "unnecessary litigation." Agencies would need to spend more time and resources addressing legal challenges instead of regulating. There is a possibility that regulatory agencies will not be able to execute program goals because they are forced to respond to confining court orders as the result of litigation (OMB 2011).

The debate over whether Congress should enact legislation to promote judicial review of regulations is an important one as the US government continues to work towards improving its regulatory regime. Most rhetoric focuses on how judicial review affects the outcomes of regulations. There is less appreciation for how judicial review affects the development of regulations. Specifically, this paper will determine whether judicial deadlines designed to make regulatory action speedier might be associated with measures that imply less comprehensive regulatory analysis. In other words, a policy to promote regulatory effectiveness through the increased use of judicial deadlines may unintentionally yield negative social outcomes if judicial deadlines could reduce the comprehensiveness of regulatory analysis.

This paper uses objective observable measures related to the development of the regulation as a proxy for "comprehensive" regulatory analysis. A "comprehensive" regulatory analysis is one that examines all regulatory alternatives, costs, and benefits during the rulemaking process. This paper examines how regulations with judicial and statutory deadlines differ on measures that imply comprehensiveness and determine whether these differences are statistically significant. The researcher uses data on 
comprehensiveness to test the research hypothesis: there is a difference in the measures that imply comprehensiveness of regulatory analysis for regulations with judicial as opposed to statutory deadlines.

\section{Judicial Deadlines and Regulatory Policy}

Deadlines have a specific impact on when a regulatory agency issues a rule. Gersen and O'Connell (2008) measured how long it took regulatory agencies to issue regulations when faced with deadlines. The authors found a statistically significant difference between how long it takes to develop regulations with and without deadlines (Gersen and O'Connell 2008). Still, this research does not imply anything about the comprehensiveness of the regulatory analysis. Regulations may be issued faster under deadlines, but the analysis could be just as comprehensive without them.

Judicial deadlines not only alter the timing of regulations but also the extent of agency analysis. Biber (2008) makes a theoretical argument that agency resource constraints could limit the comprehensiveness of regulatory development. Biber theorizes that agencies may formally, or informally, budget a certain amount of resources in terms of time, money, and labor on developing particular regulations. In situations where deadlines force agency action, regulatory agencies will likely need to move forward with regulations that they would otherwise take more time to develop (Biber 2008).

Carpenter and Grimmer's (2012) research effectively tests whether Biber's theory can be found in the real world. They examined the length of US Food and Drug Administration (FDA) approval times for drugs under review. The researchers compared approval times for drugs when deadlines were and were not present. They found that review times were faster for drugs reviewed under deadlines because the FDA spent less time on analysis. Carpenter and Grimmer argue that deadlines speed up the timing of regulatory development because they force regulatory agencies to place a greater value on time as a resource. The authors elaborate that regulatory agencies have less time to construct a satisfactory analysis as the basis for the regulation (Carpenter and Grimmer 2012). Deadlines then might not only speed up the time it takes for regulatory agencies to issue regulations but also the underlying analysis.

Deadlines have an effect on the timing of interagency review within the Executive Branch. The Office of Information and Regulatory Affairs (OIRA) in the US Office of Management and Budget reviews regulations for compliance with various Executive orders. OIRA, furthermore, leads review of regulations from executive agencies as well as other entities within the Executive Office of the President. The public and officials from government entities often have comments and questions related to the development and outcomes of proposed regulations. It is OIRA's responsibility to take the lead on this part of regulatory development. McLaughlin and Ellig (2012) empirically measured how deadlines affected OIRA review times. By measuring the length of time between the start and end of OIRA review for rules with and without deadlines, the authors concluded that regulations with deadlines have shorter OIRA review times (McLaughlin and Ellig 2012). McLaughlin and Ellig discovered that judicial deadlines can also affect the length and rigor of OIRA review. Given deadlines, OIRA and other interagency reviewers have less time to review a regulation and act on concerns regarding the rule. Reviewers of a proposed rule, in turn, have less time to identify all of the costs and benefits of a regulation and less time to discuss regulatory alternatives with the issuing agency. Shapiro and Morrall (2011) go further by examining the quality of regulatory analyses during rulemakings with deadlines. The researchers scrutinized EPA Regulatory Impact Analyses (RIAs): documents that 
present the regulatory analysis that the EPA used as the basis for individual rulemakings. An EPA RIA should include the costs and benefits that the EPA measured and monetized, as well as the regulatory alternatives that it seriously considered. To measure the quality of RIAs, Shapiro and Morrall constructed a quality scale. This scale was based on factors that would imply an extensive and well-analyzed regulation such as the RIA having a discussion of all regulatory alternatives to a policy problem (Shapiro and Morrall 2011).

After scoring about a decade's worth of RIAs from the EPA, Shapiro and Morrall concluded that time made a difference in terms of the quality of RIAs. The amount of time that an agency had to analyze a rule and the amount of time that OIRA had to review a rule both had a positive relationship with the quality of regulatory analysis (Shapiro and Morall 2011). Since judicial deadlines imposed by judicial review can reduce the time that agencies and OIRA have to review rules, it follows that these time constraints could hurt the quality of regulatory analysis and, by extension, its comprehensiveness.

The literature implies that there is a tradeoff between speed and comprehensiveness. Regulatory agencies may act more rapidly when faced with deadlines but could have less comprehensive regulatory analysis. It is pertinent to understand why this potential tradeoff is meaningful. It is also important to discuss what makes judicial deadlines unique in this context.

The RAA rests on the premise that judicial deadlines are often the most accessible way for policy makers and the public to pushback on regulatory agencies (Gattuso 2011). Currently, if a rule is seen as unnecessarily burdensome, Congress has the authority to repeal it through the Congressional Review Act (1996). For Congress to repeal a regulation under the Congressional Review Act, it must pass a resolution that is signed by the President. But, it is unlikely that the President would sign a resolution repealing a regulation that he already put in place. These obstacles to repealing regulations explain why judicial review is seen as an efficient way for regulated entities to respond to a rule.

Outside of acting as a check against burdensome rules, judicial review can be used when a regulation does not meet program goals. To illustrate, in January 2008 the state of New York led a lawsuit against the US Department of Energy (DOE) over whether energy efficiency standards for furnaces were stringent enough. The state of New York argued that by setting lax standards, DOE was withholding energy savings and environmental benefits to the public that would likely result from more efficient furnaces. DOE has a statutory obligation that requires it to set the strictest standard that is economically feasible. The state of New York therefore argued that DOE broke the law by not setting a stronger standard and the court agreed (Depalma 2008). As the court reasoned in this situation, judicial deadlines are a mechanism to assure the public that regulatory agencies comply with judicial decisions in a reasonable amount of time so that program goals can be met.

Regulatory agencies are often subject to deadlines established in the statute that authorizes a proposed regulation. It is possible that an agency will miss this legally obligated deadline for a variety of reasons. Beneficiaries of a rule who are waiting for the government to issue a regulation might sue in order to force the government to take action in order to realize potential regulatory benefits (Pierce 1997; Staszewski 2009). Ideally, judicial deadlines would decrease the time that the public needs to wait to take advantage of the benefits from potential regulations. One of the earliest uses of judicial review for this purpose came in 1978 when the state of Illinois sued the EPA for missing a statutory deadline to set standards for disposing solid hazardous waste. The state of Illinois contended that by its inaction, the EPA was withholding sizeable health and environmental benefits to the public. 
The court sided against the EPA and set a date by which the EPA must issue standards (Pierce 1997). This case exemplifies how judicial review can be an important check held by the public. If regulations are harming the public, for example, by withholding potential public benefits, litigation is a fair way for the public to respond. Deadlines become crucial to ensuring that an agency responds to the needs of the public in a timely and effective manner.

Alternatively, the courts might not strongly consider why an agency missed a statutory deadline when setting judicial deadlines. If a regulatory agency misses a statutory deadline it may have done so by either: (1) not having enough time and resources to develop a satisfactory regulation, or (2) having the time and resources to develop a satisfactory regulation but choosing not to issue one. These two reasons have disparate implications for how an agency would respond to a judicial deadline (Biber 2008).

In his research, Biber (2008) studied court orders that force agencies to reverse decisions not to regulate in a particular area. For example, in 2007 the Supreme Court decided on a lawsuit led by the state of Massachusetts against the EPA. The state of Massachusetts argued that the EPA was in breach of the Clean Air Act by deciding that it could not regulate greenhouse gasses as air pollutants. The Supreme Court ruled in favor of the states. The Supreme Court not only found that the EPA ought to regulate greenhouse gasses, but also used a court order to force the EPA to consider regulation of greenhouse gasses as air pollutants under the Clean Air Act (Cornell 2007).

Biber (2008) concludes that in situations like the state of Massachusetts' lawsuit, there can be negative outcomes associated with judicial review. Judicial deadlines can be particularly influential in this context because they, in essence, reallocate limited agency resources. An agency may have previously decided not to put resources towards regulating a par- ticular area in favor of other regulatory priorities. A judicial deadline that forces an agency to act also forces that agency to allocate resources to an area that it has not budgeted for. This type of constraint could divert limited resources from potentially more important priorities.

This idea that judicial deadlines augment agency resource constraints is at the crux of the White House's objection to the RAA (OMB 2011). Judicial deadlines can force agencies to move resources away from one rule and towards another. It is possible that this resource allocation would yield negative outcomes in other regulatory programs. Carpenter and Grimmer (2012) found that in the presence of deadlines, the FDA was more likely to approve drugs that they should not have. To compensate for the additional resources towards a judicially reviewed rule, the FDA had to delay analysis and action related to other rules (Carpenter and Grimmer 2012). In addition to the time constraints that agencies might face, limited resources lead to changes in the way regulations are analyzed. With judicial deadlines, agencies are given a set amount of time to analyze data and construct rules. Abbott (1987a, $1987 \mathrm{~b}$ ) theorizes that agencies would focus mostly on the area of concern by litigants when responding to judicial deadlines. The author argues that since an agency would respond to a judicial deadline from being sued over one issue, that agency will need to ensure that this issue is satisfactorily analyzed in the issued regulation (Abbott 1987a, 1987b). Considering the state of New York furnace standards lawsuit mentioned earlier, if states sue DOE for not setting the standard strict enough, then most of the regulatory process would focus on the strength of the standard. The regulatory agency may not adequately recognize other important concerns that were not part of the lawsuit, such as decreased competition throughout the furnace manufacturing industry. It is possible that agencies may use their limited resources to address the issue central to the lawsuit 
at the expense of other important regulatory concerns (Abbott 1987a, 1987b). These constraints extend to interagency review led by OIRA. As McLaughlin and Ellig (2012) have demonstrated, rules with deadlines have shorter OIRA review times than those without deadlines. From a legal context, Steinberg (1986) concludes that if the judiciary can set deadlines that significantly limit OIRA review, it is an unfair limit on presidential power. Steinberg argues that OIRA is an extension of the President as its regulatory review is an administration's quality control over regulations (1986). From a policy perspective, Steineberg's argument is relevant because one of OIRA's major technical purposes is to review regulations relative to Executive orders (1986). Shapiro and Morrall (2011) find that OIRA review can improve consistency and quality across agency policies. OIRA review, resultantly, plays an important role in discussing costs, benefits, and regulatory alternatives that might be overlooked without interagency review.

In writing about his personal experiences over decades at OIRA, Fraas (2011) acknowledged that rules with judicial deadlines tended to be more complicated. This complexity made rules with judicial deadlines particularly difficult to review in a truncated timeframe. In particular, Fraas contends that OIRA often could not lead a comprehensive review of rules in the face of judicial deadlines because they could only focus on a few aspects of a rule. OIRA review would focus largely on "big-picture" issues related to a rule, increasing the propensity that a meaningful problem with a regulation might slip through the cracks because OIRA and the regulatory agency could not work out a solution (Fraas 2011). This constraint on the extent and scope of regulatory analysis might be at the crux of why rules designed to prevent spills from oil and gas facilities have the capacity to burden dairy farmers.

\section{Methodology and Data}

There are a variety of positive and negative outcomes associated with judicial review and judicial deadlines. On one hand, judicial review is an important way for the public to respond to unnecessary regulatory burdens and bring about valuable regulatory benefits. On the other hand, judicial deadlines can hamper the time and quality of regulatory analyses. In order to understand how judicial deadlines affect regulatory development, this analysis will examine if regulations with judicial deadlines really are developed differently. The researcher can have a richer discussion of the role of judicial deadlines if he can determine whether potential negative outcomes found in the literature are specific to judicial review and judicial deadlines, or, instead, are a necessary result of deadlines in general.

\section{Data}

The researcher used three distinct measures that imply comprehensiveness as a proxy for comprehensiveness. In order to measure if a regulatory analysis fully considered regulatory alternatives and costs and benefits, the researcher collected data on: (1) the number of days OIRA review, (2) the number of pages in the Federal Register (FR) publication of a final rule, (3) and the number of days between a regulation's Notice of Proposed Rulemaking (NOPR) in the FR and final publication. These data points are available through three government websites: (1) Reginfo.gov, (2) Regulations.gov, and (3) the FR online. The length of OIRA review is an important proxy for comprehensiveness. President Obama has described a threefold purpose for OIRA review: "to ensure consistency with Presidential priorities, to coordinate regulatory policy, and to offer a dispassionate and analytical 'second opinion' on agency actions" (The White House 2009). With OIRA review, agencies can consider more regulatory alternatives, conduct more analysis, and provide the public with more comprehensive justifications for selected actions. 
Inter-agency discussion over rules is often complex and revolves around some of the more difficult or controversial aspects of a rule. Changes to rules are sometimes the result of long discussions between the issuing agency, OIRA and other federal entities. In response to Shapiro and Morrall's (2011) research, it is reasonable to expect that longer OIRA review times reflect longer or more involved discussions about aspects of a rule. These discussions have a tendency to create more comprehensive regulatory analyses. Based on Shapiro and Morrall's work, the length of OIRA review is an important measure of comprehensiveness because it so strongly implies comprehensiveness.

OIRA review of a final rule consists of four procedural steps. First, the issuing agency submits the final rule electronically to OIRA. Second, OIRA must accept the submitted rule for review. Third, OIRA reviews the rule and supporting analysis, coordinating with other agencies as appropriate. Finally, OIRA concludes the review, allowing for publication (or some other action) by the issuing agency. The researcher relied on the received and concluded dates reported in RegInfo.gov to determine the length of OIRA's review by calculating the differences between the date of receipt and the date of conclusion. There may be circumstances where this period does not reflect actual review time. OIRA frequently has contact with agencies before a final rule is submitted which might constitute some sort of "informal" OIRA review. This informal review could contribute to a more comprehensive rule. While excluding these informal interagency discussions may understate the influence of OIRA review, this time period is captured in the third metric below (the length of time between publication of the proposed and final rules).

After OIRA review, agencies publish their final regulations in the FR along with a preamble that often: describes the rule and its development, provides a statutory justification for the rule, responds to comments received on the proposal, and presents an analysis of the expected effects of the regulation. The number of pages in the final rule could be seen as a proxy of how comprehensively the agency developed the regulation and its supporting analysis. More pages in the FR detail greater analysis on the part of the agency in determining the appropriate regulatory action. Agencies are subject to various Executive orders and must explain why they are compliant with all that are relevant. An issuing agency may use more pages to explain consideration of more regulatory alternatives or a further explanation of the reasoning behind a regulatory decision. FR pages also must detail agency compliance with the relevant statutory requirements that an agency needed to meet to issue a regulation. More FR pages would imply more comprehensive explanations of compliance with various Executive orders and statutes. A lengthier preamble for a final rule may indicate a more comprehensive and transparent regulation even though this analysis may be independent of the actual complexity or quality of the rulemaking. The FR sequentially numbers pages with page one starting at the beginning of a calendar year. The researcher calculates the number of the FR pages occupied by each rule in the sample to populate this measure.

Issuing a final rule nevertheless only represents just one step in the US regulatory process. NOPR (also published in the FR) usually precedes final rules. A semi-annual Unified Agenda of Regulatory and Deregulatory Actions also might list regulations under development. These FR publications invite comment from the public and generally represent the beginning of the regulatory process. Measuring the time difference from when a NOPR is published in the FR to when the final rule is published will allow the researcher to measure the discussion that occurs outside of the official OIRA review time of the final rule. Greater consideration of public comment, regulatory alternatives, and concerns with a proposed rulemaking all 
contribute to a more comprehensive final rule. Given agency resource constraints and the complexity of regulatory activities, greater time between FR announcement and FR publication should connote greater time devoted to analysis. In the face of a deadline that must be met and given the research of McLaughlin and Ellig and Shapiro and Morrall (2012; 2011) it is difficult to view shorter time frames as more efficient rather than less comprehensive. To measure this time period, the researcher used the government website Reginfo.gov to record the difference between the date of NOPR publication and the date of final rule publication.

In the end, the researcher compiled a database of 72 economically significant final EPA regulations submitted to OIRA between 1995 and 2011. Of these, 47 rules had a judicial deadline and 25 had a statutory deadline. The researcher noted the type of deadline, the length of OIRA review, the number of pages in the final rule published in the FR, and the length of time between the NOPR's publication date in the FR and the FR publication of the final rule.

\section{Method of Analysis}

The researcher tested whether judicial deadline regulations differed from statutory deadline regulations on measures that implied comprehensiveness. To get a value closer to the actual measures, the researcher calculated the means for each of the measures for regulations with statutory and judicial deadlines respectively. After taking the mean difference of the variables, the researcher performed a Ttest to determine whether the differences were statistically different from zero. The T-test results would explain whether there was a difference between the average measures that imply comprehensiveness for judicial and statutory deadline regulations.

\section{Results}

Table 1 shows the means for the three measures for regulations with judicial and statutory deadlines and the differences of those means. The mean length of OIRA review was found to be, on average, 23 days longer for statutory deadline rules. The mean length of FR pages

Table 1: T-test results of the comprehensiveness of regulations with deadlines.

\begin{tabular}{llll} 
& $\begin{array}{c}\text { OIRA Review } \\
\text { Period } \\
\text { (Calendar Days) }\end{array}$ & FR Pages & \multicolumn{1}{c}{$\begin{array}{c}\text { FR publication } \\
\text { period } \\
\text { (Calendar Days) }\end{array}$} \\
\hline Statutory & 53 & 89 & 814 \\
& $(7.672)$ & $(15.669)$ & $(161.291)$ \\
Judicial & {$[26.327]$} & {$[78.344]$} & {$[806.456]$} \\
& 30 & 71 & 506 \\
& $(7.672)$ & $(5.954)$ & $(38.509)$ \\
Difference & $23^{* *}$ & {$[40.821]$} & {$[264.008]$} \\
N & 72 & 18 & 308 \\
Notes: i) ** p<0.05; ii) Data from Reginfo.gov; iii) All regulations \\
were economically significant EPA regulations submitted to OIRA \\
after 1995; iv) Standard errors are in parentheses; v) Standard \\
deviations are in brackets.
\end{tabular}


for the published final rule was 18 pages longer for statutory deadline rules. The mean length of time between the NOPR publication and publication of the final rule was, on average, 308 days longer for statutory deadline rules than judicial deadline rules. After calculating t-statistics for the analyzed mean differences, only the mean difference in the length of OIRA review was found to be statistically significant at the five-percent level.

In terms of magnitude, the differences in review and rulemaking times are quite large. Considering that OIRA review is often supposed to be two or three months, these times could relatively make a difference. The differences in FR pages though do, however, seem relatively small. It is unclear what difference 18 pages would denote from regulatory analysis. These mean differences suggest that judicial deadline rules differ from statutory rules on measures that imply comprehensiveness. All of the variables measured indicated that statutory deadline rules were found to imply that on average, they were more comprehensive than judicial deadline rules.

The researcher can only conclude that OIRA review is shorter for judicial deadline rules than statutory deadline rules. While the other variables showed mean differences in the expected direction, these differences were not statistically different from zero. Still, it is possible that in reality these differences in measures implying comprehensiveness are telling considering that there was such a relatively small sample. This sample was constrained by the availability of data and the need to prevent potentially strong selection biases from the analyzed regulations.

In analyzing regulations with different types of deadlines, it is important to acknowledge the potential selection biases. There might be something inherently different about regulations with judicial deadlines that affect comprehensiveness aside from the judicial deadline. The researcher attempted to control for potential biases through screening. As discussed earlier, previous quantitative research has shown that OIRA treats regulations with and without deadlines differently. The overall regulatory process also may differ for regulations with and without deadlines. For example, regulations with deadlines might be given priority at OIRA since there is a legal obligation to finish the review at a certain time. Both statutory and judicial deadlines may cause agencies to consider fewer alternatives or provide less time to consider public comment. To prevent potential biases, the sample of regulations only includes regulations subject to statutory or judicial deadlines. According to Executive Order 12866, regulations with annualized costs or benefits over 100 million dollars or that significantly affect a sector of the economy are economically significant and require a Regulatory Impact Analysis (The White House 1993). In general, one would expect economically significant regulations to demand longer reviews, more supporting documentation in the FR preamble, and take longer to issue. These rules might score higher on the three measures of comprehensiveness simply because they are economically significant. The level of costs and benefits provide a greater incentive for the agency, OIRA, and the public to demand more comprehensive justification and analyses. Similarly, by conducting a Regulatory Impact Analysis, the regulation itself will be supported by a more in-depth examination of the rule's costs and benefits. To prevent a potential bias, non-economically significant rules were not included in the sample of regulations.

Different federal agencies also have different regulatory styles stemming from different statutory authorities, political pressures, and corporate cultures that have evolved over time. The frequency of litigation over regulations may also vary by agency. To avoid capturing factors that are intrinsic in an agency's practice but unrelated to the deadline itself, the researcher chose to focus on regulations issued by a single agency, the EPA. The 
EPA tends to issue many economically significant rules with both statutory and judicial deadlines. The EPA also issues regulations that are different in nature from other agencies. It would be difficult, for example, to compare the way that the government determines how to regulate interest rate swaps between investment banks and the way that the government regulates coal burning power plants.

The sample was also constrained by time and availability. The FR only has published regulations issued at the beginning of 1995 online. Being able to look at the FR directly is an important part of analyzing regulations because the researcher must be able to see the regulation that will be included in the sample. To facilitate the analysis and to make sure that all regulations analyzed could be accessed, only rules submitted to OIRA after 1995 were considered in this analysis. The screening process may have developed considerable variability in two of the measures. In the case of pages in the FR publication of the final rule, there is a positive skew as the median count of pages is almost 17 pages less than the mean. The median length of time between NOPR publication and FR publication of the final rule is much shorter than the mean. In considering the range of data for these measures, both have large standard deviations from the mean and, thus, large variances. Future research calculating these statistics with different samples might net different results.

With such large variance statistics and with constraints on sample size, it is possible that the actual relationship between the measures and type of deadline is stronger than the researcher was able to determine. If the researcher was able to use a larger sample, the statistical tests might have had different results. This point is important because the direction of the mean differences is as the researcher expected. Future researchers should strive to find ways to increase the sample size while not increasing the susceptibility to a selection bias.
Future researchers might consider expanding the time period of the regulations analyzed and controlling for time effects. It is possible that presidential administrations or factors specific to a particular period of time might influence the measured statistics. One way to do this would be to expand the agencies examined. While there might be some sizeable differences between the Department of Transportation and the EPA, for example, the differences between the EPA and DOE may not be as significant. This concern might be addressed by working backwards: looking for review on specific issues rather than finding these issues within an agency. Future researchers might also discuss changing the cost/ benefit threshold to include rules that may have large costs but that are not classified as economically significant.

\section{Conclusion}

The researcher examined the implications on whether regulations with judicial deadlines will be less comprehensive than those with statutory deadlines because prior research has indicated that judicial deadlines allow for less time and resources for analysis. Some believe that using public policy to promote judicial review will reduce the effect of burdensome regulations. Yet, if judicial review promotes less comprehensive rules, then judicial review may not necessarily prevent negative outcomes associated with regulations.

The mean difference in OIRA review time was the one measure of comprehensiveness that was statistically conclusive. Statistical testing implies statutory deadline rules are reviewed longer than ones with judicial deadlines. As a result, future research could evaluate the effectiveness of regulations in meeting statutory goals. This type of analysis could more accurately explain the outcomes of this paper. If OIRA review is shorter for judicial deadline rules, are these review periods somehow less effective independent of how the regulation is writ- 
ten? While it is often difficult to measure performance of a regulatory program, it would be relevant to examine whether judicial deadlines could be less effective in preventing certain types of pollution, for example. This study only examines one part of the regulatory process: how a rule is developed. Future researchers could examine what happens after development.

Research could also be conducted outside of policy and in politics. Political scientists have shown that interest groups "venue shop" the policies they are promoting (Baumgartner and Jones 1993). These groups are likely to petition a variety of institutions until they find one that will enact their preferred policy. Such groups may have difficulty getting a product banned by the EPA, so they may start petitioning the Federal Trade Commission. Political scientists could find it useful to study the strategy behind why interest groups use litigation to meet their own regulatory goals.

In conclusion, there is currently a large push to change US regulatory policy in the hopes of making the regulatory regime more responsive to both the economy and the public (Chamber 2011a, 2011b; Obama 2011b). Unfortunately, the debate on how to make the US regulatory system more effective seems to focus solely on the more visible regulatory outcomes. There is less discussion of regulatory development. The government needs to acknowledge that there can be unintended consequences associated with regulatory reform. Policy makers must make changes to ensure that the regulatory agencies can respond effectively to structural changes in US regulatory policy. Without this consideration, policy makers run the risk of less detailed regulatory analyses and more numerous regulatory errors. Policy makers ought to recognize the effect that structural changes to US regulatory policy will have on the ability of regulatory agencies to continue to conduct high-quality and comprehensive regulatory analysis. In order to maintain the effectiveness of regulatory agencies, policy makers may need to strongly consider how policies, such as the RAA, might augment already meaningful resource constraints on regulatory analysis. Without an understanding of the tradeoff between the speed of government action and its comprehensiveness, efforts to reform regulatory policy may be as effective as crying over spilled milk.

\section{References}

Abbott, Alden F. 1987a. "The case against federal statutory and judicial deadlines: A cost-benefit appraisal”. Administrative Law Review 39 : 171-204.

- - . 1987b. Case studies on the costs of federal statutory and judicial deadlines. Administrative Law Review 39 : 467-98.

Baumgartner, Frank R., and Bryan D. Jones. 1993. Agendas and instability in American politics. Chicago: University of Chicago Press.

Biber, Eric. 2008. "The importance of resource allocation in administrative law". Administrative Law Review 60 (1): 1-71.

Carpenter, Daniel, and Justin Grimmer. 2012. "The downside of deadlines." Harvard-MIT Data Center. Accessed March 24. http://people.hmdc.harvard. edu/ dcarpent/Downside.pdf.

Chamber (United States Chamber of Commerce) 2011a. "Multi-industry letter supporting H.R. 3010, the regulatory accountability act of 2011." Accessed December 1, 2011. http://www.uschamber.com/sites/default/files/hill-let ters/110922_Multi-Industry_RegulatoryAccountabilityActof2011_Smith_Co ble_Peterson_Portman_Collins_Pryor.pdf.

- - . 2011b. "US chamber applauds house passage of regulatory accountability act." 
Accessed December 2, 2011. http://www.uschamber.com/press/releas es/2011/december/us-chamber-applauds-house-passage-regulatory-account ability-act.

Cornell (Cornell University Law School Legal Information Institute) 2007. "Massachu setts v. EPA.” Accessed February 1, 2012. http://www.law.cornell.edu/supct/ html/o5-1120.ZD.html.

The Congressional Review Act of 1996, Public Law 5 U.S.C. § 801.

Depalma, Anthony. 2008. "City sues bush administration over heating standards." The New York Times. January 17. Accessed March 26, 2012. http://cityroom. blogs.nytimes.com/2008/01/17/city-sues-bush-administration-over-heatingstandards/.

Fraas, Artur. 2011. "Observations on OIRA's policies and procedures”.

Administrative Law Review 63 (Special Edition): 79-92.

FR Online (Federal Register Online). 2011. "Federal register: retrieve an FR page." Accessed May 1. http://www.gpoaccess.gov/fr/retrieve.html.

Gattuso, James. "The regulatory accountability act: A step toward reform”. in The Heritage Foundation [database online]. December 1, 2011. Available from http://www.heritage.org/research/reports/2011/12/the-regulatory-account ability-act-a-step-toward-reform.

Gersen, Jacob E., and Anne Joseph O'Connell. 2008. "Deadlines in administrative law.” University of Pennsylvania Law Review 156 : 923-90.

House of Representatives. H.R. 3010: The Regulatory Accountability Act. 112th. 1st sess.(2011): 1-33.

McLaughlin, Patrick A., and Jerry Ellig. 2012. "Does OIRA review improve the quality of regulatory impact analysis? evidence from the final year of the bush II administration.” Accessed March 24. http://patrickamclaughlin.files.word press.com/2012/o1/mclaughlinellig_final.pdf.

Obama, Barack. 2011a. "State of the union" (speech). Delivered January 25. Copy of manuscript from The White House, "Remarks by the President in State of Union Address.” http://www.whitehouse.gov/the-press-office/2011/01/25/ remarks-president-state-union-address.

-_-. 2011b. “Toward a 21st-century regulatory system.” The Wall Street Journal, January 18. Accessed January 30, 2010. http://online.wsj.com/article/SB10o 01424052748703396604576088272112103698.html.

- - . 2012. "State of the union" (speech). Delivered January 24. Copy of manuscript from The White House, "Remarks by the President in State of Union Address." http://www.whitehouse.gov/the-press-office/2012/01/24/remarks-presidentstate-union-address.

OMB (Office of Management and Budget) 2011. "Statement of administrative policy: H.R. 3010 - regulatory accountability act of 2011.” Accessed Decem ber 1, 2011. http://www.whitehouse.gov/sites/default/files/omb/legislative/ sap/112/saphr3010r_20111129.pdf.

Pierce, Richard J. Jr. 1997. "Judicial review of agency actions in a period of diminishi ng agency resources.” Administrative Law Review 49 : 61-94.

RegInfo.gov. 2011. "Search of regulatory review.” Accessed May 1. http://www.reginfo. gov/public/do/eoAdvancedSearchMain.

Regulations.gov. 2011. “Advanced search.” Accessed May 1. http://www.regulations. gov/\#!advancedSearch.

Shapiro, Stuart, and Jeff F. Morrall. 2011. "Does haste make waste? how long does it take to do a good regulatory-impact analysis?” The George Washington 
University Regulatory Studies Center. Accessed on February 1, 2012. http:// www.regulatorystudies.gwu.edu/images/pdf/12192011_shapiro_morrall_ good_ria.pdf.

Staszewski, Glen. 2009. "Federal inaction commission." Emory Law Journal 59 : 369422.

Steinberg, Robert E. 1986. OMB review of environmental regulations: Limitations on the courts and congress. Yale Law and Policy Review 4 : 404-25.

Sunstein, Cass. 2011. "21st-century regulation: An update on the president's regulatory reforms.” Wall Street Journal, May 25, 2011. http://online.wsj.com/article/SB 10001424052702304066504576345230492613772.html (accessed January 30, 2012).

US EPA (United States Environmental Protection Agency). 2012. "Spill Prevention, Control, and Countermeasure (SPCC) Rule.” Accessed January 30. http:// www.epa.gov/osweroe1/content/spcc/index.htm.

The White House. 1993. "Executive order 12866: regulatory planning and review." Accessed May 1, 2011. http://www.reginfo.gov/public/jsp/Utilities/ EO_12866.pdf.

- - . 2009. "Presidential memorandum of January 30, 2009, regulatory review." A ccessed May 1, 2011. http://edocket.access.gpo.gov/2009/pdf/E9-2434.pdf. WSJ (Wall Street Journal). 2011. "Land of milk and regulation.” Last Modified January 27. http://online.wsj.com/article/SB10001424052748704698004576 104040647573056.html.

Jonathan Porat is in the final year of his Master of Public Policy program at The George Washington University where he is concentrating in applied economics and regulatory policy. Jonathan has a Bachelors degree from the University of Florida with a major in economics and a minor in religion. As a graduate student, Jonathan completed an internship with the Office of Information and Regulatory Affairs at the United States Office of Management and Budget. He also acted as a research analyst and assistant project manager for the United States Department of Veteran Affairs through The George Washington University School of Public Health and Health Services. In addition, Jonathan constructs crossword puzzles for newspapers and books. He has work published in The New York Times, The Los Angeles Times, and The Penguin Classics Crossword Puzzles book.

The author thanks associate editors Tanner Daniel and Kristin Hubing for all of their hard work to make this paper ready for publication. The author would also like to thank Professors David Brunori, Dylan Conger and Joseph Cordes for their valuable feedback related to the quantitative analysis of this paper. Finally, the author would especially like to thank Professor Susan Dudley for overseeing the analysis at the heart of this paper. Professor Dudley's invaluable feedback on drafts throughout the publication process allowed for the paper to better communicate the complexities of US regulatory reform. 